Research Square
Preprints are preliminary reports that have not undergone peer review.

They should not be considered conclusive, used to inform clinical practice, or referenced by the media as validated information.

\title{
Biomarkers for Diagnosis and Post-Kasai Portoenterostomy Prognosis of Biliary Atresia: Systematic Review and Meta-Analysis
}

\author{
Lin $\mathrm{He}$ \\ University of Hong Kong \\ Dennis Kai Ming Ip \\ University of Hong Kong \\ Greta Tam \\ University of Hong Kong \\ Vincent Chi Hang Lui \\ University of Hong Kong \\ Paul Kwong Hang Tam \\ University of Hong Kong \\ Patrick Ho Yu Chung ( $\square$ chungphy@hku.hk) \\ University of Hong Kong
}

\section{Research Article}

Keywords: biliary atresia, biomarkers, liver fibrosis, Kasai portoenterostomy, cirrhosis, meta-analysis

Posted Date: March 18th, 2021

DOI: https://doi.org/10.21203/rs.3.rs-303189/v1

License: (c) (1) This work is licensed under a Creative Commons Attribution 4.0 International License. Read Full License 


\section{Abstract Objectives}

To evaluate the accuracy of biomarkers for the early diagnosis of biliary atresia (BA) and prognostic stratification after Kasai portoenterostomy (KPE).

\section{Methods}

We conducted a systematic review of PubMed, Web of Science, Embase, Scopus and OVID for English literatures reporting BA biomarkers published before August, 2020. Biomarkers selected for study was based on a good evidence-level (better than Grade B, level 2b). Screening, data extraction, and quality assessment were done in duplicate.

\section{Results}

A total of 51 eligible studies were involved for systematic review, and data from 12 of them (4182 subjects) were extracted for metaanalysis in the following 2 domains: (1) serum matrix metallopeptidase-7 (MMP-7), interleukin33 (IL-33) and y-glutamyl transferase (GGT) to differentiate BA from non-BA; and (2) aspartate aminotransferase to platelet ratio index (APRi) to predict post-KPE liver fibrosis/cirrhosis. Summary sensitivity, specificity and the area under the curve (AUC) of MMP-7 for diagnosing BA were $96 \%, 91 \%$ and 0.9847 , respectively. Summary sensitivity and specificity of IL-33 for diagnosing BA were $77 \%$ and $85 \%$, respectively. Summary sensitivity, specificity and AUC of GGT for diagnosing BA were $80 \%, 79 \%$ and 0.9645 , respectively. Summary sensitivity and specificity of APRi for predicting post-KPE liver fibrosis were $61 \%$ and $80 \%$, respectively. Summary sensitivity, specificity and AUC of APRi for predicting post-KPE cirrhosis were $78 \%, 83 \%$ and 0.8729 , respectively. Moreover, good evidence-level was shown in the investigations of serum IL-18 and IL-33 in distinguishing BA from healthy control, serum IL-18 for prognosing post-KPE persistent jaundice, and serum hyaluronic acid and MMP-7 for prognosing post-KPE significant liver fibrosis.

\section{Conclusions}

MMP-7, IL-33 and GGT are useful biomarker to assist the diagnosis of BA. APRi could be used to predict post-KPE significant liver fibrosis and cirrhosis. These non-invasive biomarkers could be integrated into the management protocol of BA.

\section{Introduction}

Neonatal jaundice is common and up to two thirds of all newborns experience this problem within the first two weeks of life[1]. While most cases are classified as physiological jaundice that is self-limiting without long-term sequalae, more serious disorders are not uncommonly encountered. Biliary atresia (BA), choledochal cyst, Alagille syndrome and progressive familial intrahepatic cholestasis are common pathological causes of neonatal cholestasis requiring a prompt surgical treatment. Approximately $80 \%$ of infants with pathological jaundice in need of surgery intervention afflict with BA[2], who requires the most urgent surgical attention as there is a narrow treatment window for this condition. Therefore, the distinction of BA from other causes of neonatal cholestasis (non-BA) is essential for an optimal outcome.

The occurrence of BA varies widely among different populations, with the highest incidence rates in Asia [3]. If untreated, affected infants manifest progressive liver disease and decease within the first two years of life[4]. A timely and uneventful Kasai portoenterostomy (KPE) can potentially restore bile flow in 30\%-80\% of BA patients but complications are common [5]. It is estimated that up to $56 \%-74 \%$ of post-KPE BA patients at their 10 years old invariably necessitate liver transplantation[6]. Despite significant advances in the management of BA, establishing an early diagnosis of BA and predicting post-KPE outcome remain two major challenges. An early diagnosis leads to a timely operation that may enhance the surgical success rate[7]. Currently, an accurate diagnosis could only be established by invasive methods such as intraoperative cholangiography and liver biopsy[8]. The diagnosis can be further confirmed by the examination of liver tissue obtained at the time of $\operatorname{KPE}[9,10]$. Post-operatively, there is a lack of objective parameters that may predict a poor prognosis. Herewith, our objective is to derive a practical strategy that utilizes non-invasive biomarkers to promote early diagnosis and recognition of patients with poor prognosis based on systematic review and meta-analysis of reported serum biomarkers. 


\section{Materials And Methods}

This systematic review and meta-analysis followed the Preferred Reporting Items for Systematic Reviews and Meta-analyses guidelines $[11,12]$. No Ethical or Institutional Review Board approval was required for this study design.

\section{Literature Search}

We conducted a computerized search in PubMed, Web of Science, Embase, Scopus and OVID databases to attain English-language articles relevant to our objective up to 1st August, 2020. The following retrieval terms were used: (("biliary atresia"[MeSH]) OR (biliary atresia)) AND (biomarker) AND (diagnosis OR prognosis OR portoenterostomy).

\section{Inclusion and Exclusion Criteria}

Studies evaluating the application of serum biomarkers in the early diagnosis or the post-KPE prognosis were considered eligible for our analysis. In addition, the articles should meet the following inclusion criteria: (1) populations-For study on the diagnosis, both BA patients and non-BA and/or healthy control (HC) groups were compared. For prognostic study, BA patients were assessed after KPE; (2) reference standard-the diagnosis of BA or the post-KPE prognostic outcomes have been compared using standard measurement including liver function and native liver survival rate. Potential citations which met any of the following criteria were excluded: (1) article type-animal experiments, review, case reports and case series including less than 10 patients, editorials, letters, comments and conference papers; (2) biomarkers that needed liver biopsy/intraoperative cholangiography/laparoscopy; (3) study population overlapped.

\section{Data Extraction}

The following data were extracted from included studies using a standardized form: (1) study characteristics-last name of the first author, publication year, study duration, country of origin, study type, and the number of patients; (2) demographic characteristics-age, the percentage of male sex; (3) biomarker characteristics-name, test sample, test method, test timeframe and cut-off value; and (4) outcome characteristics-the positive or negative correlation of the biomarkers and diagnostic performance or prognostic outcomes, and the sensitivity, specificity, positive likelihood ratio (PLR), negative likelihood ratio (NLR), diagnostic odds ratio (DOR) as well as area under the curve (AUC) of the biomarkers with/without an identified cut-off value.

\section{Quality Assessment}

The methodological quality was assessed with our tailored questionnaires in terms of the Quality Assessment of Diagnostic Accuracy Studies 2 (QUADAS-2) criteria[13]. Two reviewers (Patrick Chung and Lin $\mathrm{He}$ ) independently assessed the literature search, study selection, data extraction, and quality assessment. If there were any inconsistences, they were addressed by the third reviewer (Paul Tam).

\section{Data Synthesis and Statistical Analysis}

The primary outcome of our study was the performance of biomarkers for the early diagnosis of BA and/or the post-KPE prognosis. The ultimate purpose of this study was to present a management strategy that promotes an early diagnosis or prediction of post-KPE by selecting the appropriate biomarkers. Recommendations regarding the capability of biomarkers in precisely diagnosing BA in the early stage or prognosing post-KPE clinical outcomes were in lights of the system for evidence (eTable 1 in Supplementary materials, page 1) [14]; the biomarkers with a good evidence-level (better than $3 b$ ) would be selected into the practical strategy. We constructed $2 \times 2$ contingency tables basing on the extracted true and false positives and negatives from available studies. Summary estimates of diagnostic test accuracy data including sensitivity, specificity, PLR, NLR and DOR with their 95\% confidence intervals (Cls) were calculated by the Mantel-Haenszel method (fixed effect model) or the DerSimonian-Laird method (random effect model)[15]. A hierarchical summary receiver operating characteristic (SROC) curve with its $95 \%$ confidence region was plotted. Of note, several statistical methods were used to assess any possible bias in our meta-analysis as follows: (1) threshold effect-computation of Spearman correlation coefficient between the logit of sensitivity and logit of 1-specificity; a strong positive correlation (Spearman correlation coefficient $>0.6 ; p<0.05$ ) would indicate a considerable threshold effect[16, 17]. (2) Heterogenicity-heterogenicity that represented the variability degree in results across included studies and was evaluated by Cochran's $Q$ test and $I^{2}$ test[18]; $p$ value of Cochran's Q test $<0.10$ suggested significant heterogeneity and different cut-off intervals of $\mathrm{I}^{2}$ values with $0-25 \%, 25-50 \%, 50-75 \%$ and $75-100 \%$ respectively correspond to nonsignificant, moderate, substantial and considerable heterogeneity; the heterogenicity of the 
hierarchical SROC curve was calculated by weighted regression with Inverse Variance method (Moses' model); the result of heterogenicity test determined the pooling model selection. (3) Because of the small number of the included studies, the calculation of publication bias was unable to be operated. The AUC of SROC curve greater than 0.7 indicated a high predictive accuracy of biomarker[19]. The diagnostic meta-analysis was conducted by Meta-Disc 1.4 software (Zamora J, Muriels A, Abraira V, Madrid, Spain).

\section{Results}

\section{Literature Search}

Flow diagram of the literature-screening selection was outlined in Fig. 1. Of the 1,189 citations obtained from PubMed, Web of Science, Embase, Scopus and OIVD databases, 263 duplications, 21 conference papers, 196 reviews and 4 case reports were excluded. The remaining 705 citations were entered into Title and Abstract screening, and 600 of them were removed. After the full-text assessment of the remaining 105 studies, 55 were further omitted due to the reasons as follows: (1) 7 articles having no useful information; (2) 12 articles that belonged to BA alone without prognosis; (3) 5 articles that belonged to animal experimental study; (4) 28 articles that used biomarkers from liver or biliary tract; and (5) 2 articles that were reviews. Ultimately, 51 articles were considered eligible for systematic review[20-70]. Thirty-one studies[21-24, 31-56, 68] reported a single-center evidence of biomarkers related to BA diagnosis or post-KPE prognosis, and 8 studies $[25-30,65,66]$ provided multicenter evidence but was unable to be included for meta-analysis. The data from the remaining 12 studies were constructed with $2 \times 2$ contingency tables and the performance of biomarkers for the early diagnosis[20, $57-61,67,69,70]$ or post-KPE prognosis of BA[62-64] were evaluated. All biomarkers with evidence-level less than 3a in identifications of BA diagnosis or post-KPE prognosis were summarized (eTable 2 in Supplementary materials, page 2-3). An increasing number of studies are needed to reaffirm the performance of these biomarkers because all evidences were only documented from the individual case-control study or case series.

\section{Quality Assessment of the Included Studies}

The quality assessment of the included 12 studies based on QUADAS-2 criteria was shown in Fig. 2. In the patient selection domain, there was a high risk of bias in 7 studies because they did not avoid case-control design $[20,57,60,64,67,69,70]$. Four studies showed a high risk of bias in the index test domain because their index test results were not interpreted without knowledge of the results of the reference standard[20,60,64,70]. Five studies had a high risk of bias in the reference standard domain due to devoid of reciprocal blind between the index test and the reference standard[20,57,60,64, 70]. With reference to the flow and timing domain, six articles had a high risk of bias because intervals between the index test and the reference standard were not appropriate[20, 57, 59, 60, 67, 70], and other 3 articles showed an unclear risk of bias because these intervals were not clearly reported[58,64,69]. The applicability concerns were manifested in none of the 12 studies.

\section{Characteristics of the Included Studies}

The study and biomarker characteristics of included studies were presented in Table 1. The study characteristics in "patient-level" analysis and the demographic characteristics of included studies were summarized in Table 2. Publication date of the 12 included articles ranged from 2008 to 2020 (median: 2018); the number of case-control study was identical to that of retrospective cohort study $(n=5)$; more than half of the included studies were conducted from China[20,58,59,61, 63,69,70]. There were 4 studies investigating the diagnostic performance of matrix metallopeptidase-7 (MMP-7)[58-61], 2 studies investigating that of interleukin 33 (IL-33)[20, 57] and 3 studies investigating that of $y$-glutamyl transferase (GGT) $[60,69,70]$ in the early differentiation of BA to non-BA, and 3 studies evaluating that of aspartate aminotransferase to platelet ratio index (APRi) in post-KPE prognosis (specifically, 2 for significant liver fibrosis and 3 for cirrhosis) [62-64]. Additionally, Table 1 summarized the test method and test timeframe of biomarkers, and Table 2 represented the male sex percentage and mean age of the analyzed subjects in individual biomarker analysis. 
Table 1

Characteristics of included studies in the "study-level" analysis.

\begin{tabular}{|c|c|c|c|c|c|c|c|c|c|}
\hline Study & $\begin{array}{l}\text { Publication } \\
\text { year }\end{array}$ & $\begin{array}{l}\text { Study } \\
\text { duration }\end{array}$ & $\begin{array}{l}\text { Original } \\
\text { nation }\end{array}$ & Biomarker & $\begin{array}{l}\text { Test } \\
\text { method }\end{array}$ & Test time & $\begin{array}{l}\text { No. of } \\
\text { Cases }\end{array}$ & $\begin{array}{l}\text { No. of } \\
\text { Controls }\end{array}$ & Ref. \\
\hline \multicolumn{10}{|c|}{ Biomarkers for differentiating $B A$ to non-BA } \\
\hline Wu & 2019 & $\begin{array}{l}2008- \\
2018\end{array}$ & China & MMP-7 & ELISA & After KPE & 36 & 64 & [58] \\
\hline Yang & 2018 & $\begin{array}{l}2016- \\
2018\end{array}$ & China & MMP-7 & ELISA & Before KPE & 75 & 60 & [59] \\
\hline Lertudomphonwanit & 2017 & NA & USA & $\begin{array}{l}\text { MMP- } \\
\text { 7/GGT }\end{array}$ & ELISA & $\begin{array}{l}\text { Before/at } \\
\mathrm{KPE}\end{array}$ & 35 & 35 & [60] \\
\hline Jiang & 2019 & $\begin{array}{l}2017- \\
2018\end{array}$ & China & MMP-7 & ELISA & Before KPE & 187 & 101 & [61] \\
\hline Behairy & 2020 & $\begin{array}{l}2017- \\
2019\end{array}$ & Egypt & IL-33 & ELISA & After KPE & 30 & 30 & [57] \\
\hline Chen & 2019 & $\begin{array}{l}2016- \\
2017\end{array}$ & China & IL-33 & ELISA & Before KPE & 31 & 45 & [20] \\
\hline Rendón-Macías & 2008 & $\begin{array}{l}2000- \\
2002\end{array}$ & Mexico & GGT & NA & Before KPE & 12 & 17 & [67] \\
\hline Chen & 2016 & $\begin{array}{l}2014- \\
2016\end{array}$ & China & GGT & NA & Before KPE & 1189 & 119 & [70] \\
\hline Dong & 2018 & $\begin{array}{l}2012- \\
2017\end{array}$ & China & GGT & NA & Before KPE & 1512 & 216 & [69] \\
\hline \multicolumn{10}{|c|}{ Biomarkers for predicting post-KPE significant fibrosis } \\
\hline Ueno & 2018 & $\begin{array}{l}2015- \\
2018\end{array}$ & Japan & APRi & NA & $\begin{array}{l}\text { Regardless } \\
\text { of time }\end{array}$ & 11 & 26 & [64] \\
\hline Yang & 2015 & $\begin{array}{l}2010- \\
2013\end{array}$ & China & APRi & NA & Before KPE & 56 & 35 & [63] \\
\hline \multicolumn{10}{|c|}{ Biomarkers for predicting post-KPE cirrhosis } \\
\hline Grieve & 2013 & $\begin{array}{l}1999- \\
2010\end{array}$ & UK & APRi & NA & At KPE & 28 & 232 & [62] \\
\hline Yang & 2015 & $\begin{array}{l}2010- \\
2013\end{array}$ & China & APRi & NA & Before KPE & 10 & 81 & [63] \\
\hline Ueno & 2018 & $\begin{array}{l}2015- \\
2018\end{array}$ & Japan & APRi & NA & $\begin{array}{l}\text { Regardless } \\
\text { of time }\end{array}$ & 11 & 26 & [64] \\
\hline
\end{tabular}


Table 2

Characteristics of the included studies in the "patient-level" analysis.

\section{Characteristic}

Study type

Prospective cohort

Case-control study

Retrospective cohort

Unknown cohort

Publication date, median (range), y

Biomarkers

MMP-7

MMP-7/GGT

GGT

IL-33

APRi

Mean age of subjects in MMP-7 studies, median (range), d

Male sex of subjects in MMP-7 studies, median (range), \%

Mean age of subjects in IL-33 studies, median (range), d

Male sex of subjects in IL-33 studies, median (range), \%

Mean age of subjects in GGT studies, median (range), d

Male sex of subjects in GGT

studies, median (range), \%

Mean age of subjects in APRi studies, median 70.5 (58-83)

(range), d

Original nation

China

$7(58.33)$

1 (8.33)

1 (8.33)

1 (8.33)

$1(8.33)$

1 (8.33)

Mexico

Test time

Before KPE

7 (58.33)

1 (8.33)

Before/at KPE
Analyzed subjects, No. (\%) (N $=4182$ )

$260(6.22)$

2093 (50.05)

1792 (42.85)

37 (0.88)

523 (12.51)

70 (1.67)

3065 (73.29)

$136(3.25)$

388 (9.28)

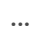

...

...

..

3726 (89.10)

70 (1.67)

$260(6.22)$

60 (1.43)

$37(0.88)$

$29(0.69)$

3655 (87.40)

70 (1.67)

Abbreviations: MMP-7, matrix metallopeptidase-7; IL-33, interleukin 33; GGT, y-glutamyl transferase; APRi, aspartate aminotransferase to platelet ratio index; M2BPGi, Mac-2-binding protein glycosylation isomer; KPE, Kasai portoenterostomy. 


\begin{tabular}{|lll|}
\hline Characteristic & Studies, No. $(\%)(\mathbf{N}=\mathbf{1 2})$ & $\begin{array}{l}\text { Analyzed subjects, No. (\%) }(\mathbf{N} \\
\mathbf{4} \text { 4182) }\end{array}$ \\
\hline At KPE & $1(8.33)$ & $260(6.22)$ \\
\hline After KPE & $2(16.67)$ & $160(3.83)$ \\
\hline Regardless of time & $1(8.33)$ & $37(0.88)$ \\
\hline $\begin{array}{l}\text { Abbreviations: MMP-7, matrix metallopeptidase-7; IL-33, interleukin 33; GGT, Y-glutamyl transferase; APRi, aspartate } \\
\text { aminotransferase to platelet ratio index; M2BPGi, Mac-2-binding protein glycosylation isomer; KPE, Kasai portoenterostomy. }\end{array}$ \\
\hline
\end{tabular}

\section{Biomarkers for differentiating BA to non-BA}

MMPs are the key enzymes that are responsible for the degradation and deposition of all protein components in extracellular matrix and basement membrane, and participate in the procedure of liver fibrosis caused by BA and other liver diseases[71]. Three retrospective cohort studies $[58,59,61]$ and one case-control study[60] suggested that BA patients experienced a significant higher level of serum MMP-7 than non-BA infants (Grade B, level 3a). Although the cut-off values used in these 4 articles were discordant, an optimal diagnostic performance of serum MMP-7 in distinguishing BA from non-BA was demonstrated: the sensitivity, specificity and AUC ranged from $95-99 \%, 83-95 \%$ and 0.96 to 0.99 , respectively (Table 3$)$. The summary sensitivity and specificity were $96 \%$ (95\% Cl: $94-$ 98\%) and 91\% (95\% Cl: 87-94\%) respectively (Fig. 3A and 3B), and PLR, NLR and DOR were 10.60 (95\% Cl: 5.48-20.52), 0.04 (95\% Cl: 0.02-0.07), 313.42 (95\% Cl: 138.89-707.28), respectively (eFigure 1A, 1B and 1C in Supplementary materials, page 5). The AUC of MMP7 for the diagnosis of BA was 0.9847 (eFigure 6A in Supplementary materials, page 10), indicating great predictive accuracy. 
Table 3

Summary of diagnostic test accuracy data in individual studies.

\begin{tabular}{|c|c|c|c|c|c|c|c|c|c|c|c|c|}
\hline Study (Year) & $\begin{array}{l}\text { Cut- } \\
\text { off } \\
\text { value }\end{array}$ & TP & FP & FN & $\mathrm{TN}$ & $\begin{array}{l}\text { Sensitivity } \\
(\%)\end{array}$ & $\begin{array}{l}\text { Specificity } \\
(\%)\end{array}$ & PLR & NLR & DOR & AUC & Ref \\
\hline \multicolumn{13}{|c|}{$\begin{array}{l}\text { MMP-7 for differentiating } B A \\
\text { to non-BA }\end{array}$} \\
\hline Wu (2019) & $\begin{array}{l}1.43 \\
\mathrm{ng} / \mathrm{mL}\end{array}$ & 35 & 11 & 1 & 53 & 97 & 83 & 5.66 & 0.03 & 168.64 & 0.96 & [58] \\
\hline Yang (2018) & $\begin{array}{l}52.85 \\
\mathrm{ng} / \mathrm{mL}\end{array}$ & 74 & 3 & 1 & 57 & 99 & 95 & 19.73 & 0.01 & $1,406.00$ & 0.99 & [59] \\
\hline $\begin{array}{l}\text { Lertudomphonwanit } \\
\text { (2017) }\end{array}$ & NA & 34 & 3 & 1 & 32 & 97 & 91 & 11.33 & 0.03 & 362.67 & 0.97 & [60] \\
\hline Jiang (2019) & $\begin{array}{l}10.37 \\
\mathrm{ng} / \mathrm{mL}\end{array}$ & 178 & 7 & 9 & 94 & 95 & 93 & 13.73 & 0.05 & 265.59 & 0.98 & [61] \\
\hline \multicolumn{13}{|c|}{$\begin{array}{l}\text { IL-33 for differentiating BA to } \\
\text { non-BA }\end{array}$} \\
\hline Behairy (2020) & $\begin{array}{l}20.8 \\
\mathrm{pg} / \mathrm{mL}\end{array}$ & 29 & 1 & 1 & 29 & 94 & 97 & 28.06 & 0.07 & 420.5 & 0.995 & {$[57]$} \\
\hline Chen (2019) & $\begin{array}{l}314.1 \\
\mathrm{pg} / \mathrm{mL}\end{array}$ & 19 & 10 & 12 & 35 & 61 & 78 & 2.76 & 0.5 & 5.54 & 0.67 & [20] \\
\hline \multicolumn{13}{|c|}{$\begin{array}{l}\text { GGT for differentiating BA to } \\
\text { non-BA }\end{array}$} \\
\hline $\begin{array}{l}\text { Lertudomphonwanit } \\
\text { (2017) }\end{array}$ & $\begin{array}{l}300 \\
U / L\end{array}$ & 24 & 6 & 5 & 25 & 83 & 77 & 3.64 & 0.23 & 16.15 & 0.9 & [61] \\
\hline $\begin{array}{l}\text { Rendón-Macías } \\
\text { (2008) }\end{array}$ & $\begin{array}{l}250 \\
U / L\end{array}$ & 10 & 5 & 2 & 12 & 83 & 71 & 3.86 & 0.27 & 14.33 & NA & [67] \\
\hline Chen (2016) & $\begin{array}{l}303 \\
\mathrm{IU} / \mathrm{L}\end{array}$ & 981 & 27 & 207 & 92 & 83 & 81 & 4.28 & 0.21 & 20 & 0.843 & [70] \\
\hline Dong (2018) & $\begin{array}{l}300 \\
U / L\end{array}$ & 1188 & 44 & 324 & 172 & 79 & 80 & 2.83 & 0.24 & 12 & 0.845 & [69] \\
\hline \multicolumn{13}{|c|}{$\begin{array}{l}\text { APRi for predicting post-KPE } \\
\text { significant fibrosis }\end{array}$} \\
\hline Yang (2015) & 0.95 & 34 & 8 & 22 & 27 & 61 & 76 & 2.66 & 0.51 & 5.22 & 0.75 & [64] \\
\hline Ueno (2018) & 0.88 & 13 & 2 & 8 & 14 & 62 & 88 & 4.95 & 0.44 & 11.38 & 0.88 & [63] \\
\hline \multicolumn{13}{|c|}{ APRi for predicting post-KPE cirrhosis } \\
\hline Grieve (2013) & 1.22 & 21 & 37 & 7 & 195 & 75 & 84 & 4.7 & 0.3 & 15.81 & 0.83 & [62] \\
\hline Yang (2015) & 1.66 & 7 & 14 & 3 & 67 & 71 & 83 & 4.05 & 0.36 & 11.17 & 0.81 & [63] \\
\hline Ueno (2018) & 0.88 & 10 & 5 & 1 & 21 & 91 & 81 & 4.73 & 0.11 & 42 & 0.88 & [64] \\
\hline
\end{tabular}

\begin{tabular}{|lll|}
\hline Biomarker & Cases & Controls \\
\hline Diagnosed & TP & FP \\
\hline Undiagnosed & FN & TN \\
\hline
\end{tabular}

Sensitivity=TP/Cases; Specificity=TN/Controls; PLR=Sensitivity/(1-Specificity); NLR=(1-Sensitivity)/Specificity; DOR=PLR/NLR. 
One of the pivotal etiologies of BA is associated with inflammatory processes where activated immune cells release proinflammatory cytokines that give rise to ongoing damage and obstruction of bile ducts and ductules[72]. Several case-control studies indicated that the serum levels of IL-33 and IL-18 in BA patients were significantly greater than those in HC children (Grade B, level 3a)[25-27, 57]. We calculated the diagnostic performance of IL-33 in identification of BA to non-BA from 2 of the 9 selected articles[20, 57]. With different cut-off values obtained from each, the sensitivity, specificity and AUC of the included articles ranged from $61-94 \%, 78-97 \%$ and 0.67 to 0.995, respectively (Table 3). The summary sensitivity and specificity were 77\% (95\% Cl: 65-87\%) and 85\% (95\% Cl: 75-92\%) (Fig. 4A and 4B), PLR, NLR and DOR were 7.78 (95\% Cl: 0.48-127.48), 0.20 (95\% Cl: 0.02-1.90) and 41.76 (95\% Cl: 0.56-3,124.11), respectively (eFigure 2A, 2B and 2C in Supplementary materials, page 6).

GGT is the most widely used biomarker for BA diagnosis in the past decades. Four retrospective cohort studies suggested that the serum levels of GGT in BA patients were significantly higher than those in non-BA infants (Grade B, level 3a) $[60,67,69,70]$, and they also provided available data to calculate the diagnostic performance of GGT in the differentiation of BA from non-BA. The sensitivity, specificity and AUC of GGT in them ranged from $79-83 \%, 71-81 \%$ and 0.843 to 0.9 , respectively, due to the different cut-off values used (Table 3). The summary sensitivity and specificity were 80\% (95\% Cl: 79-82\%) and 79\% (95\% Cl: 74-83\%) (Fig. 5A and 5B), PLR, NLR and DOR were 3.76 (95\% Cl: 3.09-4.57), 0.25 (95\% Cl: 0.23-0.28) and 15.06 (95\% Cl: 11.67-19.43), respectively (eFigure 3A, 3B and 3C in Supplementary materials, page 7). The AUC of GGT for the diagnosis of BA was 0.9645 (eFigure 6B in Supplementary materials, page 10), indicating great predictive accuracy.

\section{Biomarkers for post-KPE persistent jaundice}

Similar to the inflammatory processes that triggers the pathogenesis of BA, inflammation also plays a key role at the post-operative period. Two case-control studies found that the postoperative increase of serum IL-18 level was positively associated with the post-KPE jaundice (Grade B, 3a) $[26,27]$. The findings have suggested that serum IL-18 could be a marker for post-operative jaundice in BA patients.

\section{Biomarkers for post-KPE significant liver fibrosis}

MMPs are not only involved in the pathogenesis of BA, but also predicts the post-KPE clinical outcomes. Evidence from 4 case-control studies showed that high serum concentration of preoperative MMP-7 has a positive correlation with the severity of post-KPE liver fibrosis (Grade B, level 3a)[28, 58, 61, 66]. Serum hyaluronic acid (HA) is a high-molecular-weight glycosaminoglycan, which is produced and presented in extracellular matrix. Progressive liver diseases impair the uptake of HA and raised the concentration of serum HA [73]. Elevated serum HA level is a sensitive predictor for liver impairment. Results of some studies collectively suggested that the concentration of postoperative serum HA is associated with as the severity of liver fibrosis (Grade B, level 3a)[28-30].

Three case-control studies concluded that APRi was a sensitive biomarker to predict post-KPE liver fibrosis (Grade B, level 2a) [63, 64, 74]. We calculated the diagnostic performance of APRi in predicting the post-KPE significant liver fibrosis from 2 of these 3 studies [63, 64]. With different cut-off value of APRi, the sensitivity, specificity and AUC of 2 included studies ranged from $61-62 \%, 76-88 \%$ and 0.75 to 0.88 , respectively (Table 3). The summary sensitivity and specificity were 61\% (95\% Cl: 49-72\%) and 80\% (95\% Cl: 67-90\%), respectively (Fig. 6A and 6B), and PLR, NLR and DOR were 3.09 (95\% Cl:1.73-5.51), 0.49 (95\% Cl: 0.36-0.66) and 6.34 (95\% Cl: 2.8913.90), respectively (eFigure 4A, 4B and 4C in Supplementary materials, page 8).

\section{Biomarkers for post-KPE cirrhosis}

The progression of liver fibrosis eventually leads to the occurrence of cirrhosis for which liver transplantation is required as the only solution. If some noninvasive methods could be uncovered to predict the occurrence of cirrhosis, it enables to prevent the development of liver failure and the need of liver transplantation in BA patients effectively. Three of our included 9 studies found that APRi was a useful noninvasive tool in predicting post-KPE cirrhosis (Grade B, level 2a)[62-64]. The sensitivity, specificity and AUC of APRi with different cut-off value in these studies ranged from $71-91 \%, 81-84 \%$ and 0.81 to 0.88 , respectively (Table 3 ). The summary sensitivity and specificity were $78 \%$ (95\% Cl: 63-88\%) and 83\% (95\% Cl: 79-87\%), respectively (Fig. 7A and 7B); PLR, NLR and DOR were 4.56 (95\% Cl:3.37-6.18), 0.28 (95\% Cl: 0.17-0.46) and 16.69 (95\% Cl: 8.34-33.38), respectively (eFigure 5A, 5B and 5C in Supplementary materials, page 9). The AUC of APRi for the prediction of post-KPE cirrhosis was 0.8729 (eFigure 6C in Supplementary materials, page $10)$, indicating high predictive accuracy.

M2BPGi, also known as Wisteria floribunda agglutinin-positive human Mac-2-binding protein, was introduced as a glycol-biomarker of liver fibrosis in patients with chronic hepatitis C[75]. Recently, two studies from Japan indicated that M2BPGi was capable to predict post-KPE cirrhosis in BA (Grade B, level 2a)[64, 65].

Page 9/23 


\section{Heterogenicity and threshold effect}

Most analyses did not find significant heterogenicity in lights of the Cochran's $Q$ test and Higgins $\left.\right|^{2}$ statistic test whereas the following analyses showed substantial to considerable heterogenicity: (1) PLR ( $\left.p=0.0499, \mathrm{I}^{2}=61.0 \%\right)$ of the serum MMP-7 in BA diagnosis; (2) sensitivity $\left(p=0.0015, I^{2}=90.0 \%\right)$, specificity $\left(p=0.0136, I^{2}=83.6 \%\right), \operatorname{PLR}\left(p=0.0055, I^{2}=87.0 \%\right), \operatorname{NLR}\left(p=0.0014, I^{2}=90.2 \%\right)$ and DOR $\left(p=0.0011, I^{2}=90.6 \%\right)$ of serum IL-33 in BA diagnosis (eTable 3 in Supplementary materials, page 4). The Spearman correlation coefficient found no threshold effects in the analyses of MMP-7 in BA diagnosis and APRi in predicting cirrhosis, and the weighted regression of their SROC curves showed no heterogeneity (eTable 4 in Supplementary materials, page 4).

\section{Discussion}

The existing diagnostic methods of BA diagnosis rely on invasive procedures such as surgical exploration and operative cholangiogram and all pre-operative tests are unreliable. Although Kasai operation offers potential bile drainage, it has a narrow treatment window and a large proportion of patients suffer from on-going problems including persistent cholestasis, portal hypertension, liver fibrosis and cirrhosis. The monitoring of persistent jaundice requires continued measurements of total bilirubin while liver fibrosis is traditionally evaluated by liver biopsy. Therefore, a management strategy comprising non-invasive measures that promote early diagnosis and recognition of complications is beneficial. Serum biomarkers as a screening or prognostic tool has been widely used in other conditions such as degenerative and malignant diseases. Various biomarkers for BA have been reported but there is a lack of high-level evidence to confirm their values. Herewith, we conduct a systematic review and meta-analysis that investigates the most appropriate non-invasive biomarkers for diagnosing BA and predicting post-KPE outcomes.

Inflammation, as a trigger factor, can cause an autoimmune response against antigens from biliary epithelium[76]. Immune-mediated biliary injury is characterized by an overexpression of histocompatibility antigens on bile ducts and an obvious infiltration of immunologically active T lymphocytes, which is a central feature of adult liver diseases and also related to obstruction of neonatal extrahepatic bile ducts. Our study confirms the diagnostic performance of serum IL-33 in early diagnosis of BA and provides the good evidence-level of IL-18 for predicting post-KPE persistent jaundice. IL-33 and IL-18 are the two most closely related and bestcharacterized members of IL-1 family[77]. Dong et al[25] found that serum IL-33 level in BA patients $(791.0 \pm 22.22 \mathrm{pg} / \mathrm{mL}) \mathrm{was}$ significantly higher than that in non-BA $(607.1 \pm 20.68 \mathrm{pg} / \mathrm{mL})$ and $\mathrm{HC}(588.5 \pm 27.71 \mathrm{pg} / \mathrm{mL})$ groups (both $p<0.001)$, but no significant difference was observed between non-BA and HC groups $(p>0.05)$. One study by Vejchapipat and colleagues [26] pinpointed that serum IL-18 concentration of medium-term BA survivors was elevated, which significantly increased with the severity of post-KPE persistent jaundice $(p=0.004)$. Taken together, inflammatory factors and autoimmune response are both involved in the etiology and disease progression of BA.

The diagnostic performance of serum MMP-7 in early diagnosis of BA and its good evidence-level for predicting post-KPE significant liver fibrosis are presented in our study. Of note, the collection of serum MMP-7 was prior to the implementation of KPE. Using serum MMP-7 as a reliable biomarker to diagnose BA in clinical setting attributes to its high specificity (95-99\%) and sensitivity (83-95\%)[5861]. $y$-glutamyltransferase (GGT) as one of the factors measured in biochemical liver function tests is also utilized to differentiate BA from non-BA; at a cut-off value of 250-303IU/L, the sensitivity and specificity were $82.8-83.3 \%, 70.6-81.6 \%$, respectively[60, 67, 70], suggesting that the diagnostic accuracy of MMP-7 is significantly optimized to that of GGT. Wu et al.[58] showed that there was a positive correlation between serum MMP-7 level and the severity of liver fibrosis in infants with cholestasis at a mean age of 1.5 months, indicating that MMP-7 was likely useful for the prediction of post-KPE liver fibrosis in young BA patients. Furthermore, MMP-7 protein was found to be significantly elevated in BA patients with persistent cholestasis and liver fibrosis [78-80]. Therefore, MMP-7 is a very valuable biomarker both for BA diagnosis and post-KPE prognosis.

Despite no biomarkers with good evidence-level related to post-KPE portal hypertension, we found that serum HA and APRi had good evidence-level in association with post-KPE liver fibrosis. HA as a linear polysaccharide is responsible for liver fibrogenesis; hepatic production of it is predominantly completed in hepatic stellate cells and myofibroblast-like cells [81]. The serum HA level in HC children is low but in BA patients is significantly increased[35], suggesting that HA is potentially used as a biomarker to differentiate BA from HC. Additionally, the concentration of serum HA is positively correlated to the severity of post-KPE cirrhosis and its complications in BA patients [29], such as ascites or esophageal varices that both reflect the clinical characteristics of portal hypertension.

APRi was first introduced as a noninvasive tool by Wai and colleagues in 2003 to predict significant liver fibrosis and cirrhosis in adults with chronic hepatitis C[82], and has been employed as a biomarker in the evaluation of liver fibrosis in BA patients[62, 83]. It is 
calculated as serum aspartate aminotransferase level $(\mathrm{U} / \mathrm{L}) /$ upper normal $\times 100 /$ platelet count $\left(10^{3} / \mu \mathrm{L}\right)[82]$. In our current metaanalysis, a high diagnostic accuracy of APRi for predicting post-KPE significant liver fibrosis and cirrhosis is proposed. Early reports suggested that postoperative APRi might help the predictions of post-KPE esophageal varices and native liver survival in BA patients [84, 85]. Nevertheless, it is worth mentioning that no correlation between preoperative APRI and native liver survival is observed [68]. One study of Yang et al[63] further showed that preoperative APRI was significantly correlated to post-KPE Metavir scores (a scoring system to quantify liver fibrosis) in BA patients, and could prognose post-KPE persistent jaundice and cirrhosis. Similarly, serum M2BPGi has been confirmed as a novel biomarker for predicting post-KPE cirrhosis in BA patients; the AUC of it (0.93) is higher than that of APRi (0.81) and fibrosis-4 index (FIB-4) (0.59) [64, 65]. A study of Kuno [75] found that serum M2BPGi was also a sensitive biomarker for predicting significant liver fibrosis and cirrhosis in adults with chronic viral hepatitis, and the performance of predicting cirrhosis was superior to FIB-4 and HA. Our present study consistently demonstrates a high diagnostic accuracy of M2BPGi in the prediction of postKPE cirrhosis in BA patients.

Based on our analysis, we propose management strategy using biomarkers for the diagnosis and monitoring of BA (Fig. 8). The best cutoff value of biomarkers, if obtainable, is selected in terms of the largest value of AUC. A high concentration of serum IL-33 or IL-18 distinguishes BA patients from newborns with $\mathrm{HC}$. The differentiation of BA to non-BA can be hinted by measuring the levels of serum MMP-7, IL-33 and GGT. Regarding the prediction of post-KPE prognosis a higher serum IL-18 level indicates the occurrence of persistent jaundice while an increased value of APRi, preoperative serum MMP-7 level or postoperative serum HA level predicts the occurrence of significant liver fibrosis. The value of APRi or postoperative serum M2BPGi higher than the best cut-off value suggests liver cirrhosis.

Nonetheless, biomarkers are not without limitations. If biomarkers are universally employed to screen BA, it may increase the socioeconomic burden even though it can save more time than other screening policy like stool color cards that are already practiced in Mainland China, Japan and Taiwan[86]. Furthermore, it is still unclear of the best cut-off value of IL-18 to differentiate BA from HC and predict persistent jaundice.

We acknowledged a number of limitations in our study. Our meta-analysis included all currently available English-language literatures but publication bias may exist due to the small number of papers analyzed. In addition, partial analyses found statistically significant heterogeneity that might lead to further bias. Furthermore, because only a few publications were included in the analysis of BA diagnosis with serum IL-33 and predicting post-KPE significant liver fibrosis with APRi, both analyses failed to calculate the threshold effect and obtain the SROC curves. Lastly, the present work was a diagnostic meta-analysis and all the included studies were either case-control studies or cohort studies other than randomized controlled trials, which limited the calculation of predictive values and the evidence-level of biomarkers studied.

\section{Conclusions}

Serum IL-33 and IL-18 are both useful biomarkers to differentiate BA from HC, and serum MMP-7, IL-33 and GGT are applicable biomarkers to distinguish BA from non-BA. After KPE, the biomarkers predicting the prognosis could be: (1) serum IL-18 level to predict persistent jaundice; (2) APRi, postoperative serum HA and preoperative serum MMP-7 to predict significant liver fibrosis; and (3) APRi and postoperative serum M2BPGi to prognose cirrhosis. These noninvasive biomarkers should be incorporated into the management strategy for BA.

\section{Declarations}

Conflicts of interest: All the authors have no conflicts of interest to declare

\section{Contributors' Statement Page}

Patrick Chung and Lin He conceptualized and designed the study, collected data, drafted the initial manuscript, and reviewed and revised the manuscript.

Dennis Ip and Greta Tam assisted in statistical analysis

Patrick Chung, Vincent Lui and Paul Tam critically reviewed the manuscript for important intellectual content.

All authors approved the final manuscript as submitted and agree to be accountable for all aspects of the work. 


\section{References}

1. Maisels MJ: What's in a name? Physiologic and pathologic jaundice: the conundrum of defining normal bilirubin levels in the newborn. Pediatrics 2006, 118:805-807.

2. Davenport M, Betalli P, D'Antiga L, Cheeseman P, Mieli-Vergani G, Howard ER: The spectrum of surgical jaundice in infancy. $J$ Pediatr Surg 2003, 38:1471-1479.

3. Sanchez-Valle A, Kassira N, Varela VC, Radu SC, Paidas C, Kirby RS: Biliary Atresia: Epidemiology, Genetics, Clinical Update, and Public Health Perspective. Adv Pediatr 2017, 64:285-305.

4. Hays DM, Snyder WH, Jr.: LIFE-SPAN IN UNTREATED BILIARY ATRESIA. Surgery 1963, 54:373-375.

5. Mack CL, Sokol RJ: Unraveling the pathogenesis and etiology of biliary atresia. Pediatr Res 2005, 57:87r-94r.

6. Kelay A, Davenport M: Long-term outlook in biliary atresia. Semin Pediatr Surg 2017, 26:295-300.

7. Ohi R: Surgery for biliary atresia. Liver 2001, 21:175-182.

8. Golden J, Zagory JA, Fenlon M, Goodhue CJ, Xiao Y, Fu X, Wang KS, Gayer CP: Liquid chromatography-mass spectroscopy in the diagnosis of biliary atresia in children with hyperbilirubinemia. J Surg Res 2018, 228:228-237.

9. Shen WJ, Chen G, Wang M, Zheng S: Liver fibrosis in biliary atresia. World J Pediatr 2019, 15:117-123.

10. Alisi A, de Vito R, Monti L, Nobili V: Liver fibrosis in paediatric liver diseases. Best Pract Res Clin Gastroentero/ 2011, 25:259-268.

11. Liberati A, Altman DG, Tetzlaff J, Mulrow C, Gøtzsche PC, loannidis JP, Clarke M, Devereaux PJ, Kleijnen J, Moher D: The PRISMA statement for reporting systematic reviews and meta-analyses of studies that evaluate health care interventions: explanation and elaboration. PLOS Med 2009, 6:e1000100.

12. McInnes MDF, Moher D, Thombs BD, McGrath TA, Bossuyt PM, Clifford T, Cohen JF, Deeks JJ, Gatsonis C, Hooft L, et al: Preferred Reporting Items for a Systematic Review and Meta-analysis of Diagnostic Test Accuracy Studies: The PRISMA-DTA Statement. Jama 2018, 319:388-396.

13. Whiting PF, Rutjes AW, Westwood ME, Mallett S, Deeks JJ, Reitsma JB, Leeflang MM, Sterne JA, Bossuyt PM: QUADAS-2: a revised tool for the quality assessment of diagnostic accuracy studies. Ann Intern Med 2011, 155:529-536.

14. Shekelle PG, Woolf SH, Eccles M, Grimshaw J: Clinical guidelines: developing guidelines. Bmj 1999, 318:593-596.

15. Higgins JP, Thompson SG, Deeks JJ, Altman DG: Measuring inconsistency in meta-analyses. Bmj 2003, 327:557-560.

16. Zamora J, Abraira V, Muriel A, Khan K, Coomarasamy A: Meta-DiSc: a software for meta-analysis of test accuracy data. BMC Med Res Methodol 2006, 6:31.

17. Devillé WL, Buntinx F, Bouter LM, Montori VM, de Vet HC, van der Windt DA, Bezemer PD: Conducting systematic reviews of diagnostic studies: didactic guidelines. BMC Med Res Methodo/ 2002, 2:9.

18. Liang Z, Zhang Q, Wang C, Shi F, Cao H, Yu Y, Zhang M, Liu X: Hyaluronic acid/ Hyaluronidase as biomarkers for bladder cancer: a diagnostic meta-analysis. Neoplasma 2017, 64:901-908.

19. Su LJ, Li YM, Kellum JA, Peng ZY: Predictive value of cell cycle arrest biomarkers for cardiac surgery-associated acute kidney injury: a meta-analysis. Br J Anaesth 2018, 121:350-357.

20. Chen $\mathrm{Pa}$, Zhong Zb, Jiang Hb, Chen Hb, Lyu Jc, Zhou Ld: Th17-associated cytokines multiplex testing indicates the potential of macrophage inflammatory protein-3 alpha in the diagnosis of biliary atresia. Cytokine April 2019, 116:21-26.

21. Honsawek S, Praianantathavorn K, Chongsrisawat V, Vejchapipat $P$, Theamboonlers A, Poovorawan Y: High serum matrix metalloproteinase-3 and liver stiffness in postoperative biliary atresia. Pediatr Surg Int 2011, 27:681-687.

22. Bessho K, Mourya R, Shivakumar P, Walters S, Magee JC, Rao M, Jegga AG, Bezerra JA: Gene expression signature for biliary atresia and a role for interleukin-8 in pathogenesis of experimental disease. Hepatology 2014, 60:211-223.

23. Wu JF, Kao PC, Chen HL, Lai HS, Hsu HY, Chang MH, Ni YH: A high serum interleukin-12p40 level prior to Kasai surgery predict a favourable outcome in children with biliary atresia. Liver Int 2012, 32:1557-1563.

24. Honsawek S, Chongsrisawat V, Vejchapipat PI, Thawornsuk N, Poovorawan Y: High levels of serum basic fibroblast growth factor in children with biliary atresia. Hepatogastroenterology 2008, 55:1184-1188.

25. Dong R, Dong K, Wang X, Chen G, Shen C, Zheng S: Interleukin-33 overexpression is associated with gamma-glutamyl transferase in biliary atresia. Cytokine 2013, 61:433-437.

26. Vejchapipat P, Poomsawat S, Chongsrisawat V, Honsawek S, Poovorawan Y: Elevated serum IL-18 and interferon-gamma in medium-term survivors of biliary atresia. Eur J Pediatr Surg 2012, 22:29-33. 
27. Urushihara N, Iwagaki H, Yagi T, Kohka H, Kobashi K, Morimoto Y, Yoshino T, Tanimoto T, Kurimoto M, Tanaka N: Elevation of serum interleukin-18 levels and activation of Kupffer cells in biliary atresia. J Pediatr Surg 2000, 35:446-449.

28. Irvine KM, Wockner LF, Hoffmann I, Horsfall LU, Fagan KJ, Bijin V, Lee B, Clouston AD, Lampe G, Connolly JE, Powell EE: Multiplex serum protein analysis identifies novel biomarkers of advanced fibrosis in patients with chronic liver disease with the potential to improve diagnostic accuracy of established biomarkers. PLOS ONE 2016, 11.

29. Chongsrisawat V, Kongtawelert P, Tongsoongnoen W, Tangkijvanich P, Vejchapipat P, Poovorawan Y: Serum hyaluronan as a marker reflecting the severity of cirrhosis and portal hypertension in postoperative biliary atresia. Pediatr Surg Int 2004, 20:773-777.

30. Hasegawa T, Sasaki, Kimura T, Hoki M, Okada A, Mushiake S, Yagi M, Imura K: Measurement of serum hyaluronic acid as a sensitive marker of liver fibrosis in biliary atresia. J Pediatr Surg 2000, 35:1643-1646.

31. Pang S-Y, Dai Y-M, Zhang R-Z, Chen Y-H, Peng X-F, Fu J, Chen Z-R, Liu Y-F, Yang L-Y, Wen Z, et al: Autoimmune liver disease-related autoantibodies in patients with biliary atresia. World Journal of Gastroenterology 2018, 24:387-396.

32. Rákoczi G, Takács L, Jakabfi P, Kunos I, Selmeci L, Gyuris T, Péterfy M, Verebély T, Perner F: Increased urinary dipeptidyl peptidase IV activity in extrahepatic biliary atresia. Lancet 1995, 345:864-865.

33. Song Z, Dong R, Fan Y, Zheng S: Identification of serum protein biomarkers in biliary atresia by mass spectrometry and enzymelinked immunosorbent assay. J Pediatr Gastroenterol Nutr 2012, 55:370-375.

34. Ye CJ, Wang J, Yang YF, Shen Z, Chen G, Huang YL, Zheng YJ, Dong R, Zheng S: Upregulation of High Mobility Group Box 1 May Contribute to the Pathogenesis of Biliary Atresia. Eur J Pediatr Surg 2019, 29:388-393.

35. Ukarapol N, Wongsawasdi L, Ong-Chai S, Riddhiputra P, Kongtawelert P: Hyaluronic acid: additional biochemical marker in the diagnosis of biliary atresia. Pediatr Int 2007, 49:608-611.

36. Honsawek S, Chayanupatkul M, Chongsrisawat V, Theamboonlers A, Praianantathavorn K, Udomsinprasert W, Vejchapipat P, Poovorawan Y: Serum adiponectin and transient elastography as non-invasive markers for postoperative biliary atresia. $B M C$ Gastroentero/ 2011, 11:16.

37. Honsawek S, Chongsrisawat V, Praianantathavorn K, Theamboonlers A, Poovorawan Y: Elevation of serum galectin-3 and liver stiffness measured by transient elastography in biliary atresia. Eur J Pediatr Surg 2011, 21:250-254.

38. Honsawek S, Chongsrisawat V, Vejchapipat P, Thawornsuk N, Poovorawan Y: Association of serum levels of tissue inhibitors of metalloproteinase-1 with clinical outcome in children with biliary atresia. Asian Pacific Journal of Allergy and Immunology 2006, 24:161-166.

39. Honsawek S, Udomsinprasert W, Jirathanathornnukul N, Chongsrisawat V, Poovorawan Y: Elevated serum heat shock protein 70 and liver stiffness reflect hepatic dysfunction and severity in postoperative biliary atresia. Pediatr Surg Int 2017, 33:893-899.

40. Honsawek S, Udomsinprasert W, Vejchapipat P, Chongsrisawat V, Phavichitr N, Poovorawan Y: Elevated serum periostin is associated with liver stiffness and clinical outcome in biliary atresia. Biomarkers 2015, 20:157-161.

41. Honsawek S, Vejchapipat P, Payungporn S, Theamboonlers A, Chongsrisawat V, Poovorawan Y: Soluble receptor for advanced glycation end products and liver stiffness in postoperative biliary atresia. Clin Biochem 2013, 46:214-218.

42. Minnick KE, Kreisberg R, Dillon PW: Soluble ICAM-1 (sICAM-1) in biliary atresia and its relationship to disease activity. J Surg Res 1998, 76:53-56.

43. Sirisomboonlarp K, Udomsinprasert W, McConachie E, Woraruthai T, Poovorawan Y, Honsawek S: Increased serum glypican-3 is associated with liver stiffness and hepatic dysfunction in children with biliary atresia. Clinical and Experimental Hepatology 2019, 5:48-54.

44. Soini T, Pihlajoki M, Andersson N, Lohi J, Huppert KA, Rudnick DA, Huppert SS, Wilson DB, Pakarinen MP, Heikinheimo M: Transcription factor GATA6: a novel marker and putative inducer of ductal metaplasia in biliary atresia. Am J Physiol Gastrointest Liver Physiol 2018, 314:G547-g558.

45. Udomsinprasert W, Honsawek S, Jirathanathornnukul N, Chongsrisawat V, Poovorawan Y: Elevation of serum urokinase plasminogen activator receptor and liver stiffness in postoperative biliary atresia. World Journal of Hepatology 2016, 8:1471-1477.

46. Udomsinprasert W, Kitkumthorn N, Mutirangura A, Chongsrisawat V, Poovorawan Y, Honsawek S: Association between Promoter Hypomethylation and Overexpression of Autotaxin with Outcome Parameters in Biliary Atresia. PLoS One 2017, 12:e0169306.

47. Vejchapipat P, Theamboonlers A, Poomsawat S, Chittmittrapap S, Poovorawan Y: Serum transforming growth factor-beta1 and epidermal growth factor in biliary atresia. Eur J Pediatr Surg 2008, 18:415-418. 
48. Chayanupatkul M, Honsawek S, Chongsrisawat V, Vimolket L, Poovorawan Y: Serum retinol binding protein 4 and clinical outcome in postoperative biliary atresia. Hepatology International 2011, 5:906-912.

49. Dong R, Sun S, Liu XZ, Shen Z, Chen G, Zheng S: Fat-Soluble Vitamin Deficiency in Pediatric Patients with Biliary Atresia. Gastroenterology Research and Practice 2017, 2017.

50. Dong R, Shen Z, Zheng C, Chen G, Zheng S: Serum microRNA microarray analysis identifies miR-4429 and miR-4689 are potential diagnostic biomarkers for biliary atresia. Sci Rep 2016, 6:21084.

51. Zahm AM, Hand NJ, Boateng LA, Friedman JR: Circulating microRNA is a biomarker of biliary atresia. J Pediatr Gastroenterol Nutr 2012, 55:366-369.

52. Peng X, Yang L, Liu H, Pang S, Chen Y, Fu J, Chen Y, Wen Z, Zhang R, Zhu B, et al: Identification of Circulating MicroRNAs in Biliary Atresia by Next-Generation Sequencing. J Pediatr Gastroenterol Nutr 2016, 63:518-523.

53. Hasegawa T, Kimura T, Sasaki T, Okada A: Plasma endothelin-1 level as a marker reflecting the severity of portal hypertension in biliary atresia. J Pediatr Surg 2001, 36:1609-1612.

54. Preativatanyou K, Honsawek S, Chongsrisawat V, Vejchapipat P, Theamboonlers A, Poovorawan Y: Correlation of circulating endoglin with clinical outcome in biliary atresia. Eur J Pediatr Surg 2010, 20:237-241.

55. Udomsinprasert W, Poovorawan Y, Chongsrisawat V, Vejchapipat P, Jittikoon J, Honsawek S: Leukocyte mitochondrial DNA copy number as a potential biomarker indicating poor outcome in biliary atresia and its association with oxidative DNA damage and telomere length. Mitochondrion 2019, 47:1-9.

56. Udomsinprasert W, Poovorawan Y, Chongsrisawat V, Vejchapipat $P$, Zhan D, Honsawek S: Telomere length in peripheral blood leukocytes is associated with severity of biliary atresia. PLOS ONE 2015, 10.

57. Behairy OG, Elsadek AE, Behiry EG, Elhenawy IA, Shalan NH, Sayied KR: Clinical Value of Serum Interleukin-33 Biomarker in Infants With Neonatal Cholestasis. Journal of Pediatric Gastroenterology \& Nutrition 2020, 70:344-349.

58. Wu JF, Jeng YM, Chen HL, Ni YH, Hsu HY, Chang MH: Quantification of Serum Matrix Metallopeptide 7 Levels May Assist in the Diagnosis and Predict the Outcome for Patients with Biliary Atresia. J Pediatr 2019, 208:30-37.e31.

59. Yang L, Zhou Y, Xu P-p, Mourya R, Lei H-y, Cao G-q, Xiong X-I, Xu H, Duan X-f, Wang N, et al: Diagnostic Accuracy of Serum Matrix Metalloproteinase-7 for Biliary Atresia. Hepatology 2018, 68:2069-2077.

60. Lertudomphonwanit C, Mourya R, Fei L, Zhang Y, Gutta S, Yang L, Bove KE, Shivakumar P, Bezerra JA: Large-scale proteomics identifies MMP-7 as a sentinel of epithelial injury and of biliary atresia. Science Translational Medicine 2017, 9.

61. Jiang J, Wang J, Shen Z, Lu X, Chen G, Huang Y, Dong R, Zheng S: Serum MMP-7 in the Diagnosis of Biliary Atresia. Pediatrics 2019, 144.

62. Grieve A, Makin E, Davenport M: Aspartate Aminotransferase-to-Platelet Ratio index (APRi) in infants with biliary atresia: Prognostic value at presentation. Journal of Pediatric Surgery 2013, 48:789-795.

63. Yang LY, Fu J, Peng XF, Pang SY, Gao KK, Chen ZR, He LJ, Wen Z, Wang H, Li L, et al: Validation of aspartate aminotransferase to platelet ratio for diagnosis of liver fibrosis and prediction of postoperative prognosis in infants with biliary atresia. World $\mathrm{J}$ Gastroenterol 2015, 21:5893-5900.

64. Ueno T, Kodama T, Noguchi Y, Saka R, Takama Y, Tazuke Y, Bessho K, Okuyama H: Clinical implications of serum Mac-2-binding protein (M2BPGi) during regular follow-up of patients with biliary atresia. Pediatric Surgery International 2018, 34:1065-1071.

65. Ueno T, Kodama T, Noguchi Y, Nomura M, Saka R, Takama Y, Tazuke Y, Bessho K, Okuyama H: Serum Mac-2-binding protein (M2BPGi) as a marker of chronological liver fibrosis in biliary atresia patients with cirrhosis. Pediatr Surg Int 2019, 35:1065-1070.

66. Kerola A, Lampela H, Lohi J, Heikkilä P, Mutanen A, Hagström J, Tervahartiala T, Sorsa T, Haglund C, Jalanko H, Pakarinen MP: Increased MMP-7 expression in biliary epithelium and serum underpins native liver fibrosis after successful portoenterostomy in biliary atresia. J Pathol Clin Res 2016, 2:187-198.

67. Rendón-Macías ME, Villasís-Keever MA, Castañeda-Muciño G, Sandoval-Mex AM: Improvement in accuracy of gamma-glutamyl transferase for differential diagnosis of biliary atresia by correlation with age. Turk J Pediatr 2008, 50:253-259.

68. Ihn K, Ho IG, Chang EY, Han SJ: Correlation between gamma-glutamyl transpeptidase activity and outcomes after Kasai portoenterostomy for biliary atresia. Journal of Pediatric Surgery 2018, 53:461-467.

69. Dong R, Jiang J, Zhang S, Shen Z, Chen G, Huang Y, Zheng Y, Zheng S: Development and Validation of Novel Diagnostic Models for Biliary Atresia in a Large Cohort of Chinese Patients. EBioMedicine 2018, 34:223-230. 
70. Chen X, Dong R, Shen Z, Yan W, Zheng S: Value of Gamma-Glutamyl Transpeptidase for Diagnosis of Biliary Atresia by Correlation With Age. J Pediatr Gastroenterol Nutr 2016, 63:370-373.

71. Hsieh CS, Chuang JH, Huang CC, Chou MH, Wu CL, Lee SY, Chen CL: Evaluation of matrix metalloproteinases and their endogenous tissue inhibitors in biliary atresia-associated liver fibrosis. J Pediatr Surg 2005, 40:1568-1573.

72. Arafa RS, Abdel Haie OM, El-Azab DS, Abdel-Rahman AM, Sira MM: Significant hepatic expression of IL-2 and IL-8 in biliary atresia compared with other neonatal cholestatic disorders. Cytokine 2016, 79:59-65.

73. Dhawan A, Trivedi P, Cheeseman P, Baker AJ, Howard ER, Mieli-Vergani G: Serum hyaluronic acid as an early prognostic marker in biliary atresia. J Pediatr Surg 2001, 36:443-446.

74. Suominen JS, Lampela H, Heikkilä P, Lohi J, Jalanko H, Pakarinen MP: APRi predicts native liver survival by reflecting portal fibrogenesis and hepatic neovascularization at the time of portoenterostomy in biliary atresia. J Pediatr Surg 2015, 50:1528-1531.

75. Kuno A, Ikehara Y, Tanaka Y, Ito K, Matsuda A, Sekiya S, Hige S, Sakamoto M, Kage M, Mizokami M, Narimatsu H: A serum "sweetdoughnut" protein facilitates fibrosis evaluation and therapy assessment in patients with viral hepatitis. Sci Rep 2013, 3:1065.

76. Wang J, Xu Y, Chen Z, Liang J, Lin Z, Liang H, Xu Y, Wu Q, Guo X, Nie J, et al: Liver Immune Profiling Reveals Pathogenesis and Therapeutics for Biliary Atresia. Cell 2020, 183:1867-1883.e1826.

77. Dinarello CA: Interleukin-1, interleukin-1 receptors and interleukin-1 receptor antagonist. Int Rev Immunol 1998, 16:457-499.

78. Huang CC, Chuang JH, Chou MH, Wu CL, Chen CM, Wang CC, Chen YS, Chen CL, Tai MH: Matrilysin (MMP-7) is a major matrix metalloproteinase upregulated in biliary atresia-associated liver fibrosis. Mod Pathol 2005, 18:941-950.

79. Ramachandran P, Balamurali D, Peter JJ, Kumar MM, Safwan M, Vij M, Rela M, Mahalingam S: RNA-seq reveals outcome-specific gene expression of MMP7 and PCK1 in biliary atresia. Sci Transl Med 2019, 46:5123-5130.

80. Kobayashi H, Li ZX, Yamataka A, Lane GJ, Miyano T: Clinical evaluation of serum levels of matrix metalloproteinases and tissue inhibitors of metalloproteinases as predictors of progressive fibrosis in postoperative biliary atresia patients. J Pediatr Surg 2002, 37:1030-1033.

81. Gressner AM, Schäfer S: Comparison of sulphated glycosaminoglycan and hyaluronate synthesis and secretion in cultured hepatocytes, fat storing cells, and Kupffer cells. J Clin Chem Clin Biochem 1989, 27:141-149.

82. Wai CT, Greenson JK, Fontana RJ, Kalbfleisch JD, Marrero JA, Conjeevaram HS, Lok AS: A simple noninvasive index can predict both significant fibrosis and cirrhosis in patients with chronic hepatitis C. Hepatology 2003, 38:518-526.

83. Kim SY, Seok JY, Han SJ, Koh H: Assessment of liver fibrosis and cirrhosis by aspartate aminotransferase-to-platelet ratio index in children with biliary atresia. J Pediatr Gastroenterol Nutr 2010, 51:198-202.

84. Lampela H, Kosola S, Heikkilä P, Lohi J, Jalanko H, Pakarinen MP: Native liver histology after successful portoenterostomy in biliary atresia. J Clin Gastroenterol 2014, 48:721-728.

85. Chongsrisawat V, Vejapipat P, Siripon N, Poovorawan Y: Transient elastography for predicting esophageal/gastric varices in children with biliary atresia. BMC Gastroentero/ 2011, 11:41.

86. Chung PHY, Zheng S, Tam PKH: Biliary atresia: East versus west. Semin Pediatr Surg 2020, 29:150950.

\section{Figures}


Records identified via PubMed and Web of Science retrieval $(\mathrm{n}=240)$
Additional records identified via Embase, Scopus and OVID retrieval $(\mathrm{n}=949)$

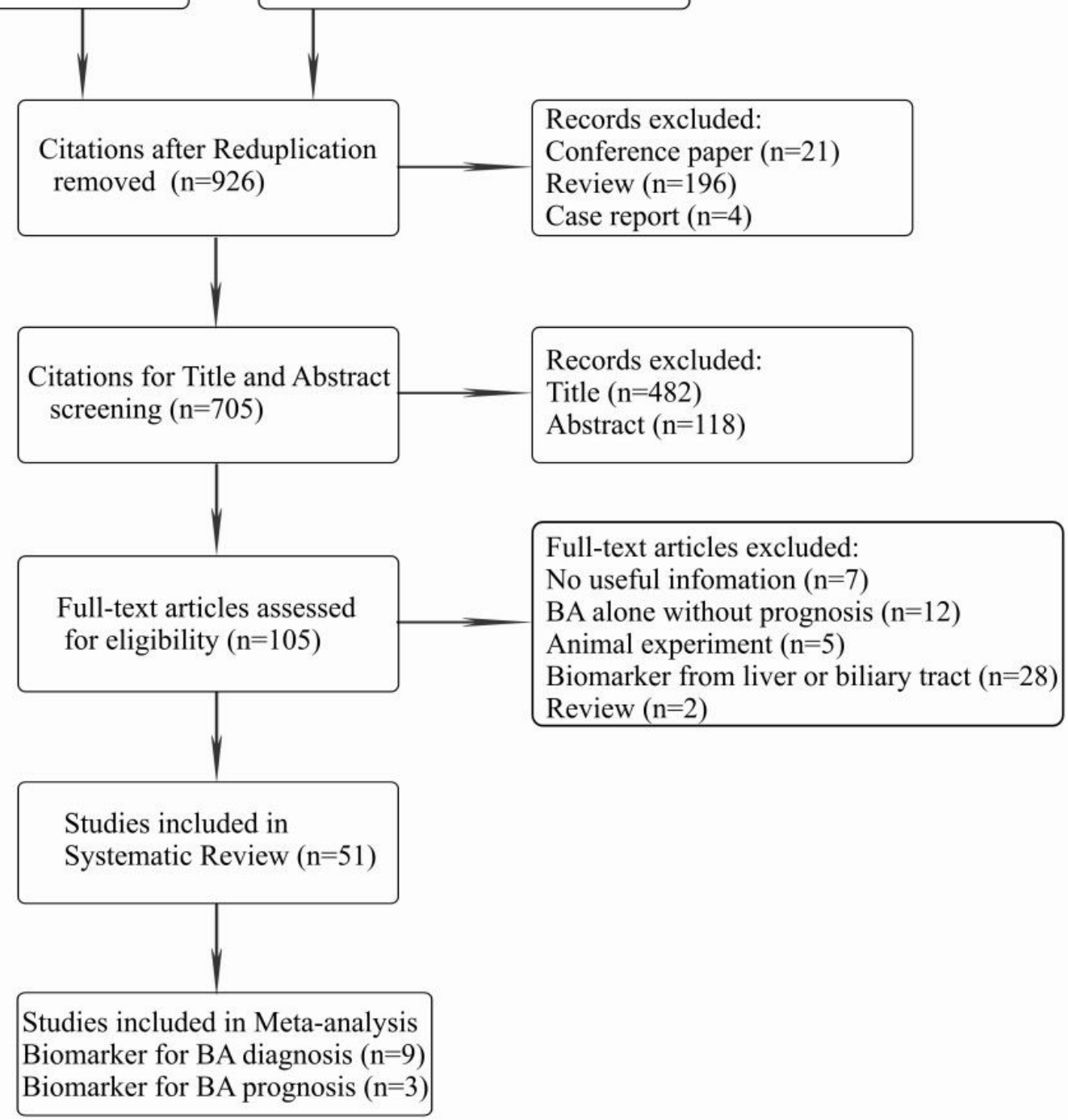

\section{Figure 1}

Flow diagram of study selection. Abbreviations: BA, biliary atresia; MMP-7, matrix metallopeptidase-7; IL-33, interleukin 33; APRi, aspartate aminotransferase to platelet ratio index. 

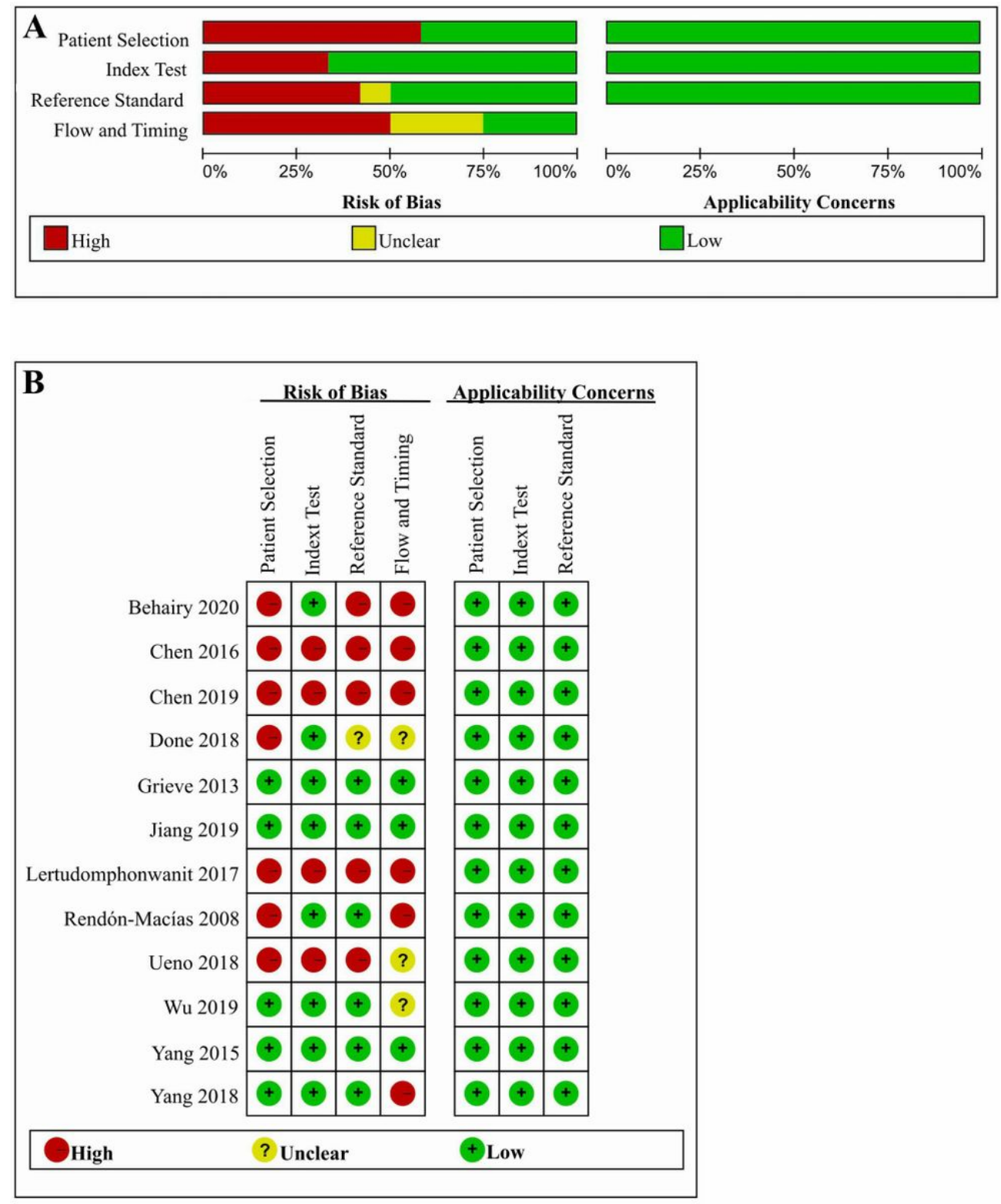

\section{Figure 2}

Quality assessment of the included studies based on QUADAS-2 criteria. A. Methodological quality graph; B. Methodological quality summary. '"' in red, ' + ' in green and '?' in yellow mean high risk, low risk and unclear risk, respectively. 
A

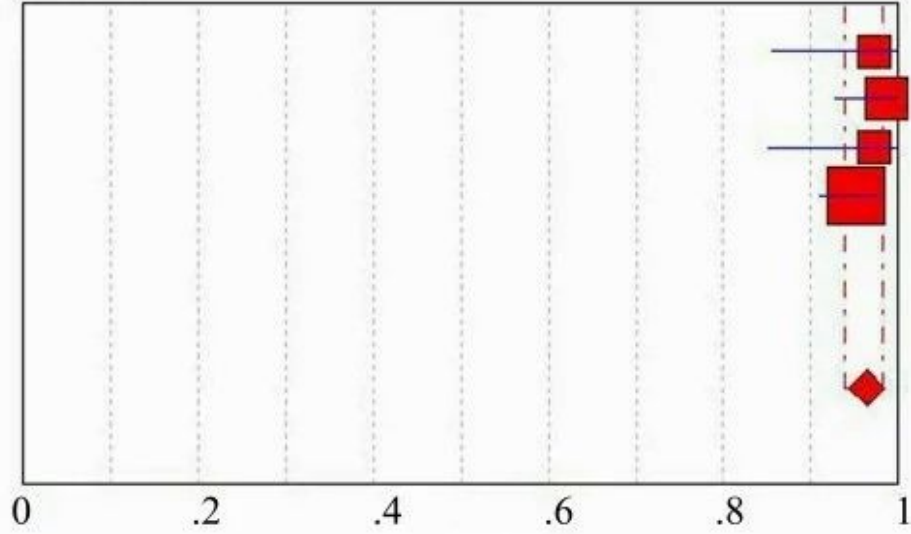

Wu 2019

Yang 2018

Lertudomphonwanit 2017

Jiang 2019

Sensitivity (95\% CI)

$0.97(0.85-1.00)$

$0.99(0.93-1.00)$

$0.97(0.85-1.00)$

$0.95(0.91-0.98)$

Pooled Sensitivity $=0.96(0.94-0.98)$

Cochran- $\mathrm{Q}=2.31 ; \mathrm{df}=3(\mathrm{p}=0.5110)$

Sensitivity

\section{B}

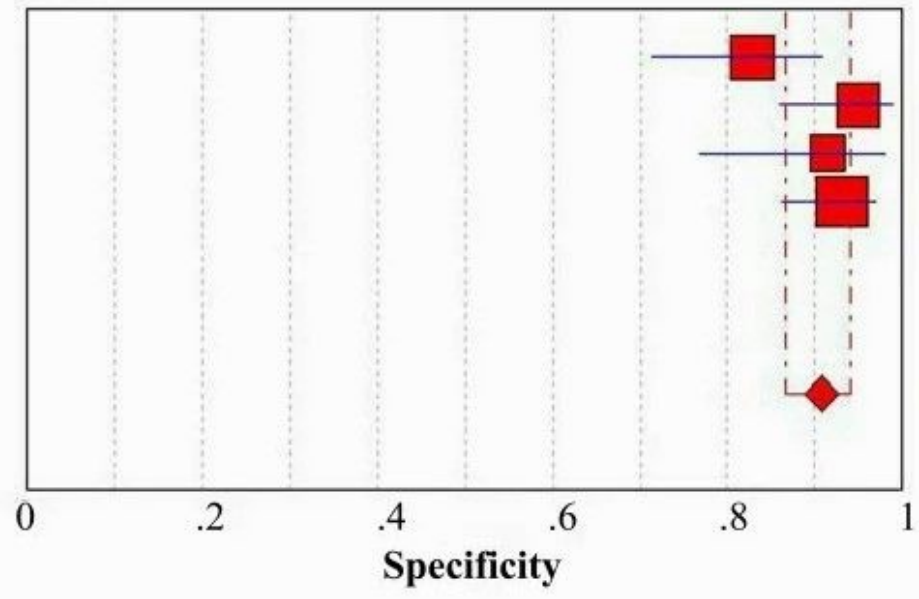

Wu 2019

Yang 2018

Lertudomphonwanit 2017

Jiang 2019

Specificity (95\% CI)

$0.83(0.71-0.91)$

$0.95(0.86-0.99)$

$0.91(0.77-0.98)$

$0.93(0.86-0.97)$

Pooled Specificity $=0.91(0.87-0.94)$

Cochran- $\mathrm{Q}=6.18 ; \mathrm{df}=3(\mathrm{p}=0.1033)$

Inconsistency (I-square) $=51.4 \%$

Figure 3

Coupled forest plots of the sensitivity and specificity of MMP-7 for BA diagnosis. A. Sensitivity of MMP-7 for BA diagnosis; B. Specificity of MMP-7 for BA diagnosis. 
A

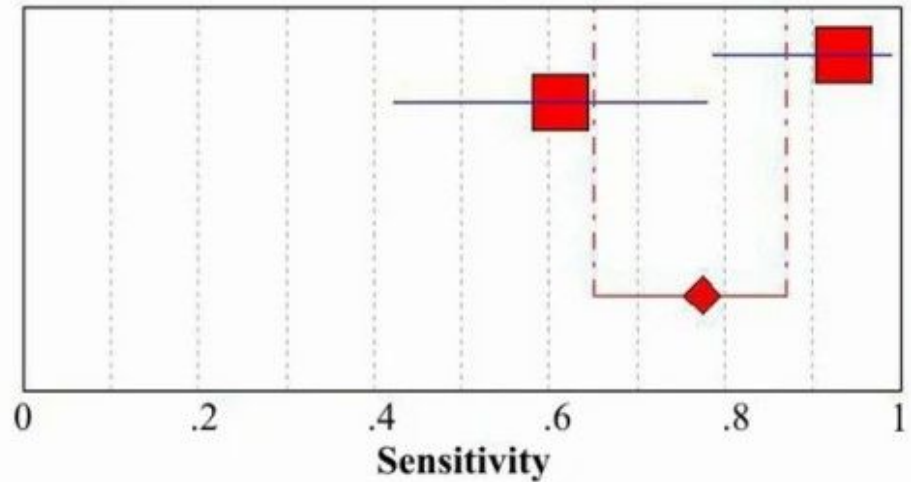

Behairy 2020

Sensitivity (95\% CI)

Chen 2019

$0.94(0.79-0.99)$

$0.61(0.42-0.78)$

Pooled Sensitivity $=0.77(0.65-0.87)$

Cochran- $\mathrm{Q}=10.02 ; \mathrm{df}=1 \quad(\mathrm{p}=0.0015)$

Inconsistency $(\mathrm{I}-$-square $)=90.0 \%$

B

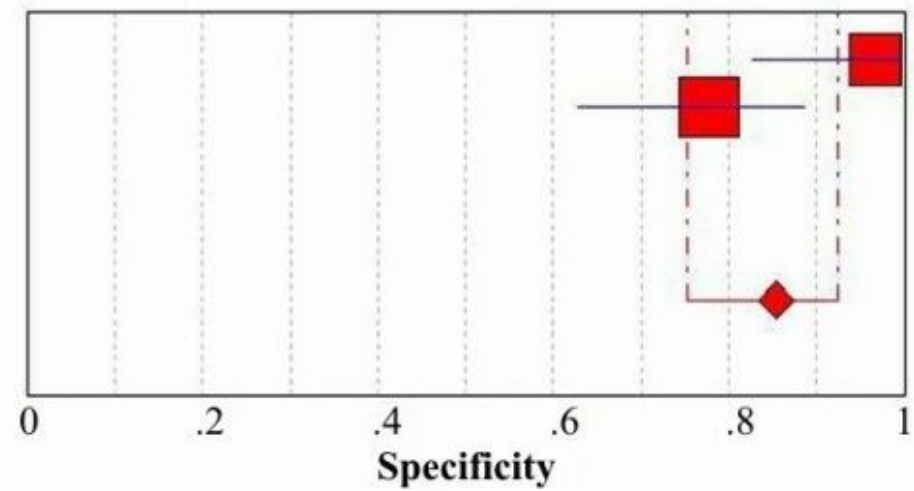

Behairy 2020

Chen 2019

Specificity (95\% CI)

$0.97(0.83-1.00)$

$0.78(0.63-0.89)$

Pooled Specificity $=0.85(0.75-0.92)$

Cochran- $\mathrm{Q}=6.09 ; \mathrm{df}=1 \quad \mathrm{p}=0.0136)$

Inconsistency (I-square) $=83.6 \%$

Figure 4

Coupled forest plots of the sensitivity and specificity of IL-33 for BA diagnosis. A. Sensitivity of IL-33 for BA diagnosis; B. Specificity of IL-33 for BA diagnosis. 


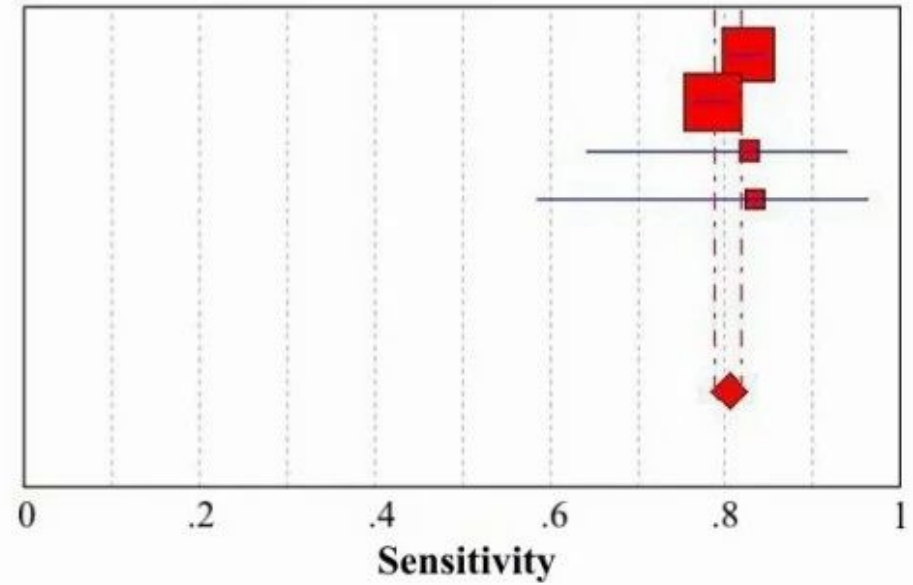

B

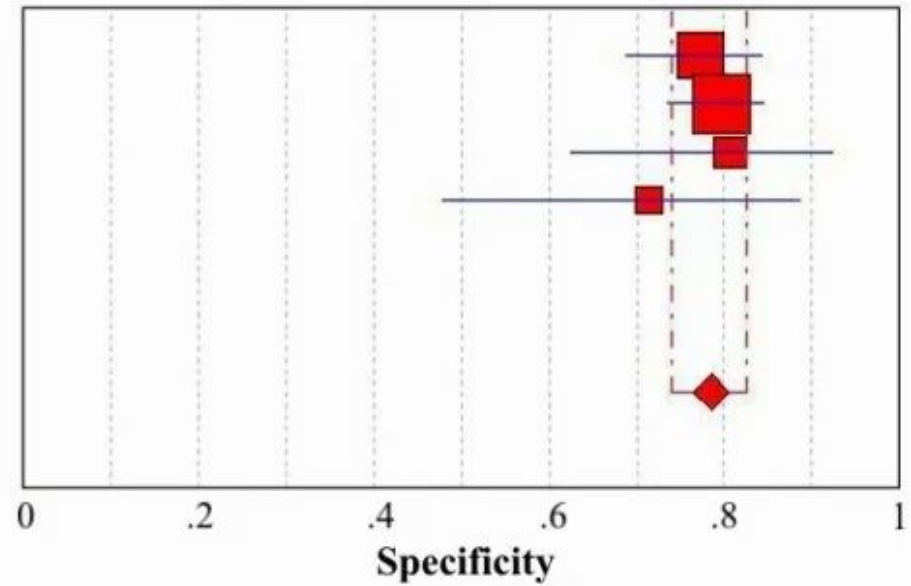

Chen 2019

Dong 2018

Lertudomphonwanit 2017

Rendón-Macías 2008

Pooled Sensitivity $=0.80(0.79-0.82)$

Cochran- $\mathrm{Q}=7.02 ; \mathrm{df}=3(\mathrm{p}=0.0713)$

Inconsistency (I-square) $=57.3 \%$
Sensitivity (95\% CI)

$0.83(0.80-0.85)$

$0.79(0.76-0.81)$

$0.83(0.64-0.94)$

$0.83(0.59-0.96)$

Pooled Sensitivity $=0.79(0.74-0.83)$

Cochran- $\mathrm{Q}=0.93 ; \mathrm{df}=3(\mathrm{p}=0.8182)$

Inconsistency (I-square) $=0.0 \%$

Specificity (95\% CI)

Chen 2019

$0.77(0.69-0.84)$

$0.80(0.74-0.85)$

$0.81(0.63-0.93)$

$0.71(0.48-0.89)$

Rendón-Macías 2008

Figure 5

Coupled forest plots of the sensitivity and specificity of GGT for BA diagnosis. A. Sensitivity of GGT for BA diagnosis; B. Specificity of GGT for BA diagnosis. 
A

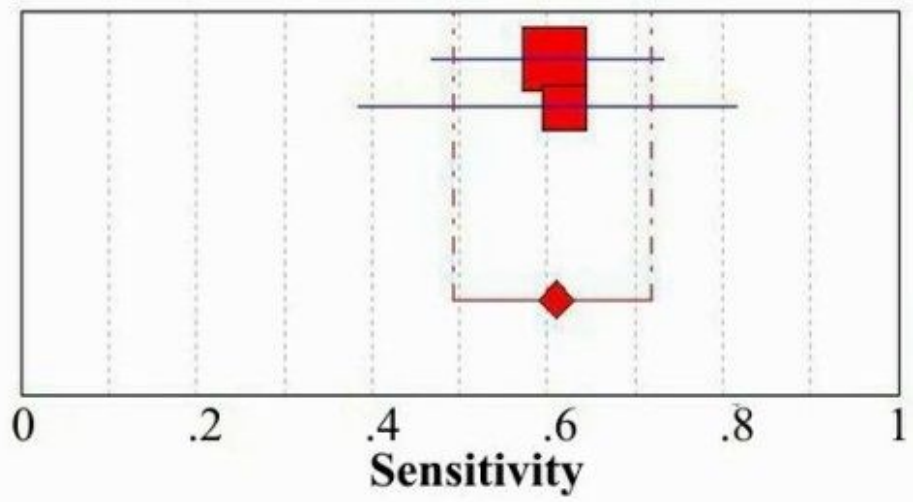

Yang 2015

Ueno 2018
Sensitivity (95\% CI)

$0.61(0.47-0.74)$

$0.62(0.38-0.82)$

Pooled Specificity $=0.61(0.49-0.72)$

Cochran- $\mathrm{Q}=0.01 ; \mathrm{df}=1(\mathrm{p}=0.9239)$

Inconsistency (I-square) $=0.0 \%$

B

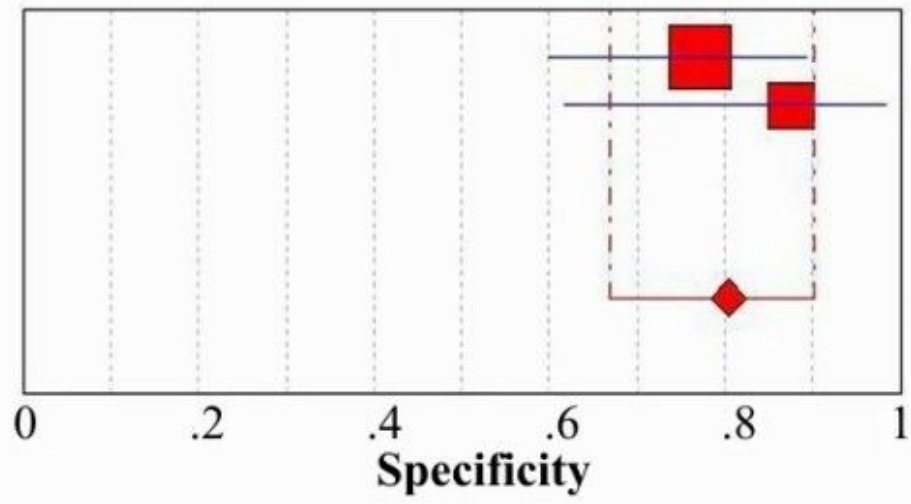

Yang 2015

Specificity (95\% CI)

Ueno 2018

$0.76(0.60-0.90)$

$0.88(0.62-0.98)$

Pooled Specificity $=0.80(0.67-0.90)$

Cochran- $\mathrm{Q}=0.80 ; \mathrm{df}=1(\mathrm{p}=0.3720)$

Inconsistency (I-square) $=0.0 \%$

Figure 6

Coupled forest plots of the sensitivity and specificity of APRi for post-KPE significant liver fibrosis and cirrhosis. A. Sensitivity of APRi for significant fibrosis; B. Specificity of APRi for significant fibrosis. 
A

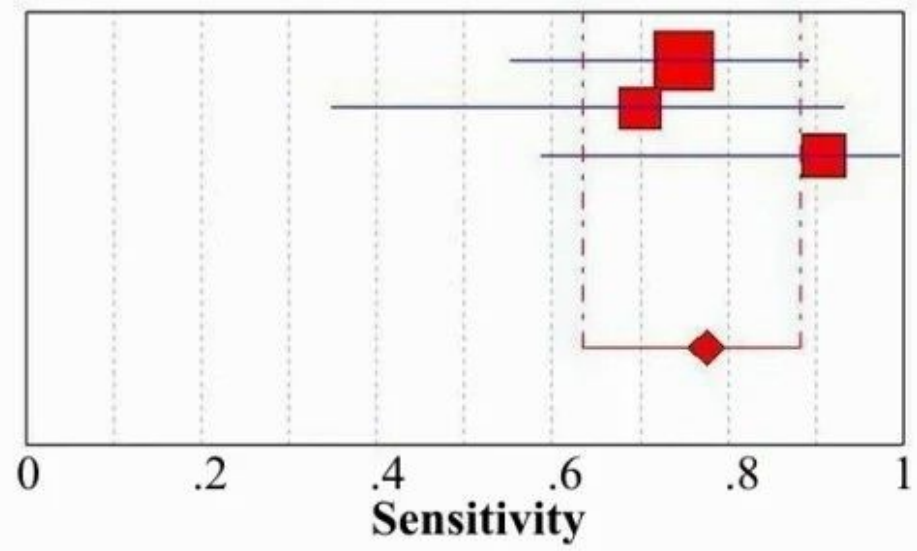

Grieve 2013

Yang 2015

Ueno 2018
Sensitivity (95\% CI)

$0.75(0.55-0.89)$

$0.71(0.35-0.93)$

$0.91(0.59-1.00)$

Pooled Sensitivity $=0.78(0.63-0.88)$

Cochran- $\mathrm{Q}=1.78 ; \mathrm{df}=2(\mathrm{p}=0.4110)$

1 Inconsistency (I-square $)=0.0 \%$

B

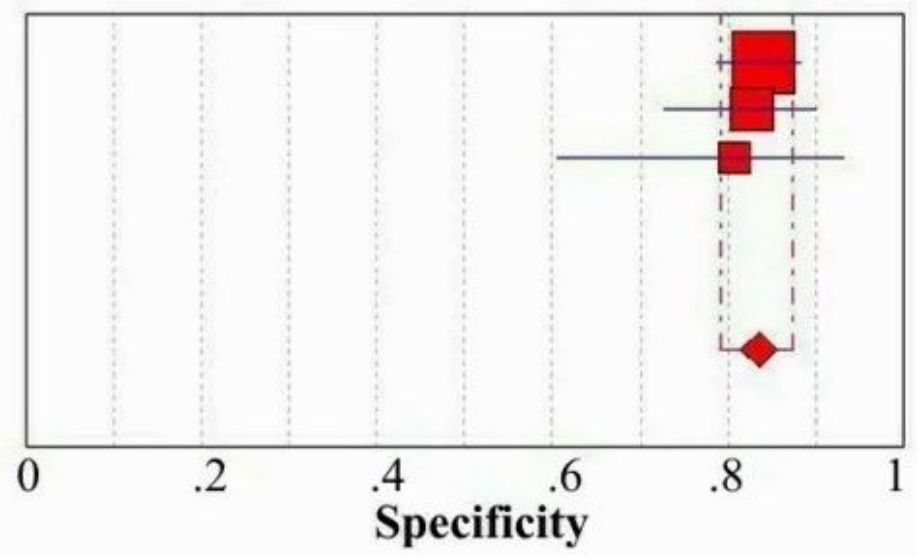

Grieve 2013

Yang 2015

Ueno 2018

Specificity (95\% CI)

$0.84(0.79-0.89)$

$0.83(0.73-0.90)$

$0.81(0.61-0.93)$

Pooled Specificity $=0.83(0.79-0.87)$

Cochran- $\mathrm{Q}=0.22 ; \mathrm{df}=2(\mathrm{p}=0.8948)$

Inconsistency (I-square) $=0.0 \%$

Figure 7

Coupled forest plots of the sensitivity and specificity of APRi for post-KPE cirrhosis. A. Sensitivity of APRi for cirrhosis; B. Specificity of APRi for cirrhosis. 


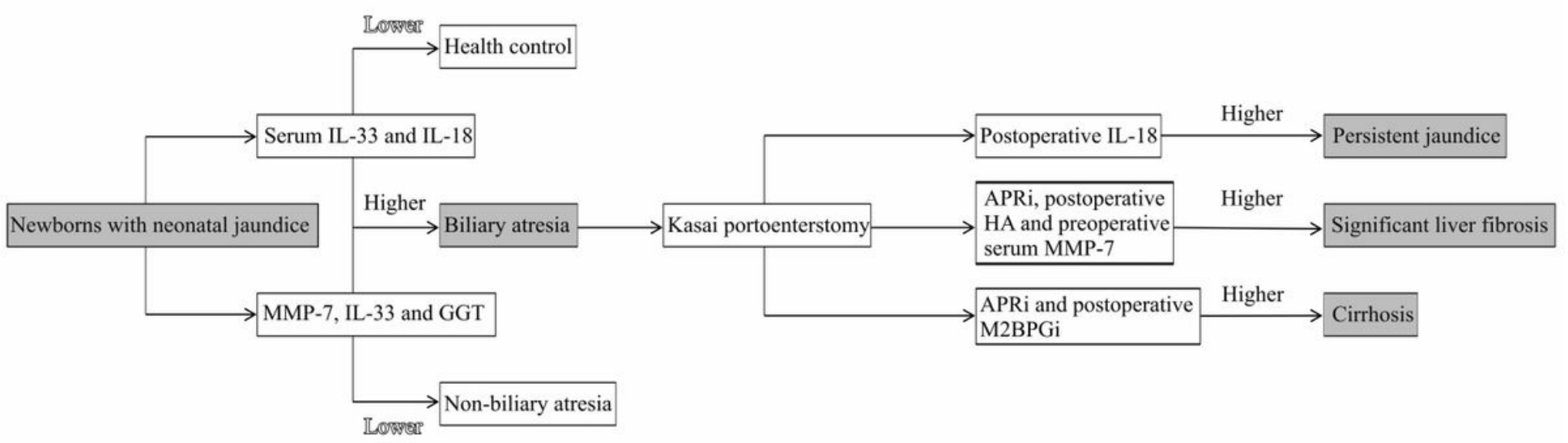

\section{Figure 8}

Flow diagram of practical strategy using biomarkers for diagnosing BA and prognosing post-KPE clinical outcomes. Abbreviations: MMP-7, matrix metallopeptidase-7; IL, interleukin; GGT, y-glutamyl transferase; HA, hyaluronic acid; APRi, aspartate aminotransferase to platelet ratio index; M2BPGi, Mac-2-binding protein glycosylation isomer. Selecting the best cut-off value is based on the largest AUC. The AUC is not provided in the investigations of serum IL-18 for diagnosing BA and prognosing post-KPE persistent jaundice. As such, the best cut-off value of it is not presented. The best cut-off values of MMP-7 for diagnosing BA and prognosing post-KPE significant liver fibrosis both are $52.85 \mathrm{ng} / \mathrm{mL}$ with the largest AUC of 0.99 [59]; the best cut-off value of IL-33 for diagnosing BA is $20.8 \mathrm{pg} / \mathrm{mL}$ with the largest AUC of 0.995[57]; the best cut-off value of GGT for diagnosing BA is $300 \mathrm{U} / \mathrm{L}$ with the largest AUC of 0.9[61]. the best cut-off value of APRi for prognosing liver fibrosis and cirrhosis is 0.88 with the largest AUC of 0.88[63]; and the best cut-off value of M2BPGi for prognosing cirrhosis is 1.84 cutoff index with the largest AUC of $0.93[64]$.

\section{Supplementary Files}

This is a list of supplementary files associated with this preprint. Click to download.

- Supplementarymaterials.doc 